\title{
Part I: Validity and reliability of a Photographic Method for Postural Assessment (P-MPA)
}

\author{
*Petronella Aletta Hough, BOT (UFS), MOT (UFS) https://orcid.org/0000-000 I-993 I-6360 \\ Lecturer, Department of Occupational Therapy, Faculty of Health Sciences, University of the Free State, Bloemfontein
}

Mariette Nel, BA (UFS), BA Hons (UFS), M Med Sc in Biostatistics https://orcid.org/0000-0002-3889-0438

Lecturer, Department of Biostatistics, School of Medicine, University of the Free State

Introduction: Good postural alignment is positively associated with safe, mechanically effective and meaningful engagement in occupations. Health care professionals assess posture in clinical settings by using a variety of methods ranging from simple visual observation, to more complex quantitative assessments of postural alignment, which are costly and mostly done in laboratory environments. The need exists for a cost effective and user-friendly method for the assessment of posture in clinical settings and research studies.

Objectives: The aim of this study was to develop a Photographic Method of Postural Assessment (P-MPA) that quantitatively measures postural alignment, and to determine the validity and reliability of the P-MPA.

Methods: A graph, representing graphic postural alignment, was used consisting of a vertical line that represents the five levels of anatomical landmarks, with a horizontal line crossing the vertical line at each of the five levels. A total of 20 points were randomly plotted on the five horizontal lines. The graph was photographed using a smartphone, and A4 sized photographs were printed. Fifty participants measured and noted the distance deviations between the points on the horizontal lines and the vertical line. The actual deviation from the vertical line was calculated using a ratio of measured to real distance.

Results: The distance deviation between measured and actual distances was statistically significant for certain anatomical landmarks as indicated by $95 \%$ Confidence Intervals and Limits of Agreement. With respect to the anatomical landmarks and respective points, no clinically significant differences were observed, as a difference of less than $10 \mathrm{~mm}$ was found.

Recommendations: It is recommended that the P-MPA be used, as a user-friendly and cost-effective method, for measuring postural alignment in clinical settings, and, that it be further developed and investigated as measurement tool for both single and multiple-joint research studies during activity performance.

Key words: Posture assessment, validity, reliability

\section{INTRODUCTION}

Good postural alignment is positively associated with safe', mechanically effective and meaningful engagement in occupations ${ }^{2}$. Health care professionals assess posture in clinical settings by using a variety of methods ${ }^{3,4,5}$ which range from simple visual observation in clinical practice ${ }^{6}$, to more complex quantitative assessments of postural alignment ${ }^{7,8,9}$. Many of these systems however proved to be timeconsuming, complex and are difficult to use outside the laboratory environment, such as in the context of community and hospital settings.

With increasing pressure for accountability on quality practices as well as ethical standards in health service delivery, methods for assessment of posture are under continuous investigation to contribute to valid and reliable assessment practices ${ }^{10}$. Rosario ${ }^{11}$ presented categories of methods of postural assessments from a study sample of 452 articles describing related technologies of Biomechanical assessment of human posture. These categories are visual observation, goniometry, photographic, radiographs, electromagnetic tracking, as well as the plumb line method. Singla and Vegar' ${ }^{\prime 2}$ and Rossario" "both found that visual observation is the most generally used method to assess posture in clinical practice. Limitations of the visual observation method are that quantitative data cannot be obtained, and minor postural alterations cannot be detected. In addition, poor interrater agreement of the visual observation method discourage the use of this method for clinical and scientific research purposes. The "gold standard" radiographic method however is costly and risks exposure towards harmful radiations, which promotes the use of non-invasive methods for the measurement of postural variables. Singla and Vegar ${ }^{12}$ argues that the advancement of photographic method and its use as a method for postural evaluation is indisputable. This method has been compared with the visual observation method, goniometry and radiography and Singla and Vigar ${ }^{12}$ and Rossario" ${ }^{1}$ recommend the use of the photogrammetric method for future studies that focus on posture evaluation.

Consistent with contemporary validity and reliability theories, the performance of a new instrument needs to be evaluated in terms of accuracy, correctness or conformity as it relates to the true context ${ }^{13}$ and value that is being measured ${ }^{14}$, as well as the consistency reflected in the measurements using the same instrument ${ }^{15,16}$.

The objectives of the current study were therefore to: (i) develop a Photographic Method of Postural Assessment (P-MPA) that quantitatively measures postural alignment, (ii) test the P-MPA in terms of the accuracy of measurements between anatomical landmarks and the line of gravity, representing validity, and (iii) test the P-MPA in terms of reproducibility, representing reliability ${ }^{15}$.

Two of the 3 types of validity as suggested by The Consensus Based Standards group for the selection of health status Measurement Instruments (COSMIN group) ${ }^{17}$ were considered in the study of the P-MPA namely content validity which includes face validity, and construct validity which includes structural validity.

The COSMIN group ${ }^{18}$ regards reliability as a key measurement property of a measurement instrument and refers to consistency as 
a prominent feature of reliable measurements. In addition, it also highlights the absence of measurement error as an important aspect of reliability. The COSMIN group further agrees on a property of reliability to be the amount of measurement error deemed acceptable for the effective clinical use of a measurement tool.

\section{METHODOLOGY}

A cross sectional study was conducted after obtaining ethical clearance from the Health Sciences Research Ethics Committee of the Faculty of Health Sciences at the University of the Free State (HSREC I53/2016 (UFS-HSD20I6/I263).

The development of Photographic Method of Postural Assessment (P-MPA) comprised four steps. Step I: A graph with measurements $1600 \times 500 \times 2 \mathrm{~mm}$ was used as a graphic representation of postural alignment (See Figure la).

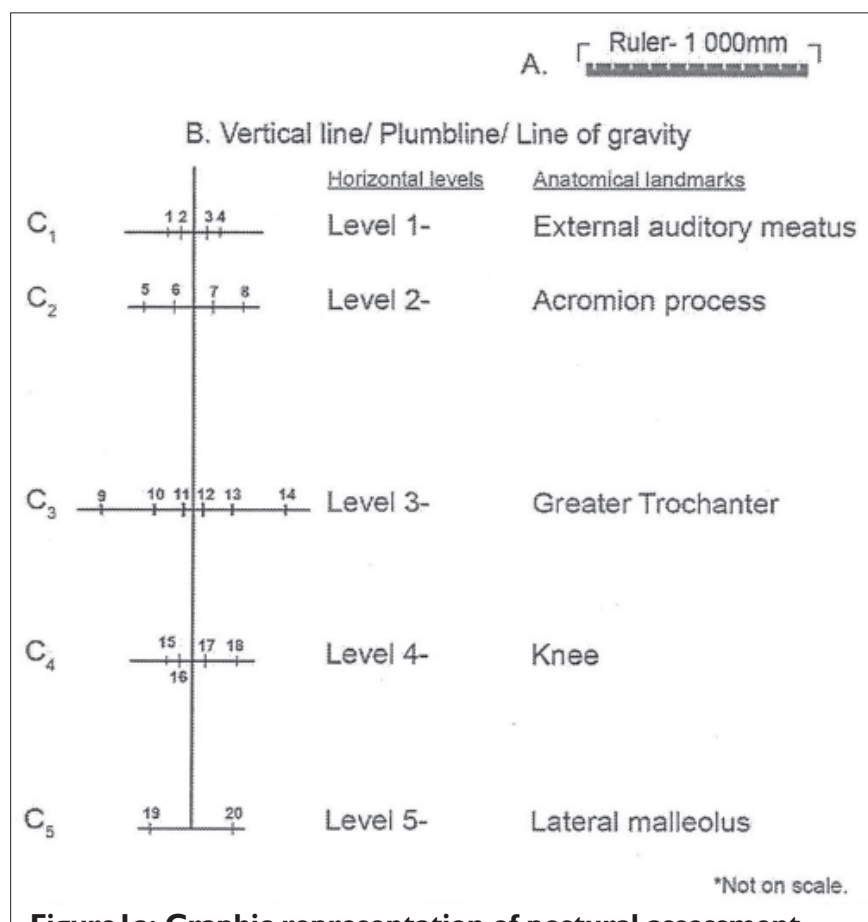

Figure la: Graphic representation of postural assessment

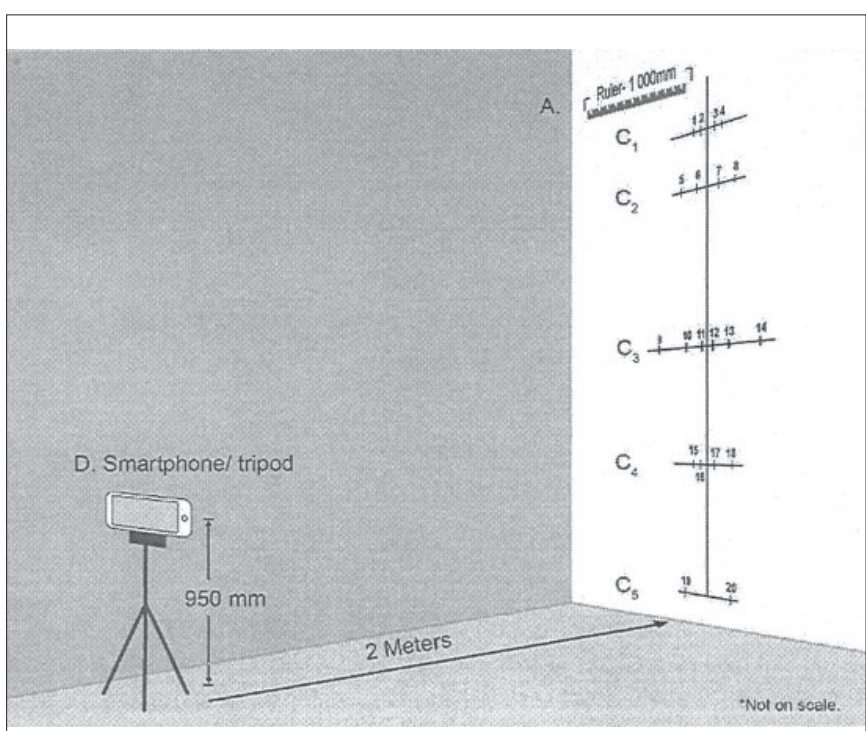

Figure Ib: Setup for taking photo of Graphic representation of postural assessment

Figure I: Photographic Method of Postural Assessment (P-MPA)
On the graph, a ruler $(A)$ was positioned indicating a real distance of $1000 \mathrm{~mm}$. A vertical line (B) represents the line of gravity (plumb line) during posture assessment, and five horizontal lines $(\mathrm{Cl}-5)$ that cut the vertical line, representing the levels of the anatomical landmarks ${ }^{19}$ namely lateral malleolus, greater trochanter, knee, acromion process and external auditory meatus. A total of 20 points were randomly plotted on the five horizontal lines, representing random possible deviations from the plumb line. The graph was mounted on a wall. Step 2: Two photographs were taken of the graph by using a smartphone(D) (Samsung, S6, I6MP, f/2.2, $31 \mathrm{~mm}$, OIS, autofocus) positioned at a right angle on a tripod at a distance of 2 meters from the graph, at the height of $950 \mathrm{~mm}$ (Figure Ib). Step 3: Two A4 printed photographs were handed to each of the 50 participants who measured the distance deviation of each of the 20 points with respect to the plumb line. These measurements were documented and transferred to an excel spreadsheet. Step 4: The actual (real) distance on photos was established by calculating the ratio of measured/real distance $x$ distance from plumb line. (see Table I on page 43 column: actual distances in $\mathrm{mm}$ 's)

Procedure: On the first day steps I and 2 were performed by the researchers, namely graph was mounted, photographed, and A4 copies were printed. On the second day (step 3), measurements were done on the photographs. Fifty participants were each issued with two A-4 sized photographs of the graph and a $300 \mathrm{~mm}$ ruler with $\mathrm{mm}$ increments. Participants were requested to (i) measure the distance in millimetres between each of the 20 points plotted on the five horizontal lines and the plumb line, and (ii) to note the measurements on a data form. After all the measurements were noted, the measurements were transferred from the data forms to an EXCELL spreadsheet by the researchers. For analysis purposes (step 4) the ratio of measured/real distance $x$ distance from the plumb line was applied to all measurements.

Data were analysed using descriptive statistics namely medians and ranges for continuous data and frequencies and percentages for categorical data. Validity and reliability were described by means of $95 \%$ confidence intervals $(\mathrm{Cl})$ for the median difference for paired data, $95 \%$ limits of agreements ${ }^{20}$.

\section{RESULTS}

Fifty university students from the department of Occupational Therapy gave informed consent to participate in the study. The median age was 20.1 years, ranging from 18.7 to 25.7 years. Most $(90 \%)$ were in their second year of study. The actual and measured distances are shown in Table I on page 44.

As depicted in Table I, results pertaining to content validity indicate that the distance deviation between measured and actual distances for both photos were statistically significant $(95 \% \mathrm{Cl})$ for landmark I: point 2, point 3 and point 4, landmark 2: point 5, point 8 , landmark 3: point 14, and landmark 4: point 18 . Statistically significant differences were also found for photo 2 at the following points, landmark 3: point $9[-6.7 ;-6]$, landmark 5: point $19[-3.3 ;-3.3]$ and point 20 [-3.3;-3.3]. Although statistically significant, no clinically significant differences were observed with respect to landmarks I -5 and the respective points mentioned above. As noted in Table I the P-MPA limits of agreement vary mostly within $10 \mathrm{~mm}$ for both photos, which indicates a high level of accuracy of the results obtained by measurements of the 20 points on the 5 horizontal landmarks in support of strong content validity.

For the purposes of this study, clinical significance was seen as $10 \mathrm{~mm}(\mathrm{Icm})$ deviation from the plumb line. Clinical significance (or relevance) is based on clinical expertise ${ }^{21}$ therefore given the researcher's clinical experience regarding posture assessment the posture deviation from the plumb line within $\mathrm{Icm}$ is viewed as clinically the same.

The reliability of the P-MPA results is given in Table II on page 44. To determine reliability, the differences between the two photos with reference to the distance measured and actual distance, were compared. 
Table I: Distance deviation between measured and actual in $\mathrm{mm}(\mathrm{n}=50)$

\begin{tabular}{|c|c|c|c|c|c|c|}
\hline Variable & Anatomical landmarks & $\begin{array}{l}\text { Actual } \\
\text { distance } \\
\text { in mm's }\end{array}$ & $\begin{array}{c}\text { Measured } \\
\text { distance in } \mathrm{mm} \text { 's } \\
\text { on photo (range) }\end{array}$ & $\begin{array}{c}\text { Median } \\
\text { difference in } \\
\text { mm's (range) }\end{array}$ & $\begin{array}{l}95 \% \mathrm{Cl} \text { for } \\
\text { the median } \\
\text { difference for } \\
\text { paired data }\end{array}$ & $\begin{array}{c}95 \% \\
\text { Limits of } \\
\text { agreement }\end{array}$ \\
\hline Photo I & I: External auditory meatus & & & & & \\
\hline Point I & & 40 & $40(33.3-40.7)$ & $0(0 ; 6.7)$ & $0 ; 0$ & $-2.4 ; 2.9$ \\
\hline Point 2 & & 21 & $20.0(20-26.7)$ & I $(-5.7 ; 1.0)$ & $1 ; I^{*}$ & $-2.6 ; 3.8$ \\
\hline Point 3 & & 30.5 & $30(26.7-33.3)$ & $0.5(-2.8 ; 3.8)$ & $0.5 ; 0.5^{*}$ & $-2.2 ; 4.1$ \\
\hline \multirow[t]{2}{*}{ Point 4} & & 61 & $60(58.3-60.0)$ & $1.0(1.0 ; 1.0)$ & $1 ; 1 *$ & $1 ; 1$ \\
\hline & 2: Acromion & & & & & \\
\hline Point $5(n=45)$ & & 106 & $106.7(106.7-113.3)$ & $-0.7(-0.7 ; 2.7)$ & $-0.7 ;-0.7^{*}$ & $-1.9 ; 1.0$ \\
\hline Point $6(n=49)$ & & 50 & $50(46.7-53.3)$ & $2.0(-3.3 ; 3.3)$ & $0 ; 3.3$ & $-1.8 ; 5.1$ \\
\hline Point 7 & & 50 & $50(46.7-53.3)$ & $0(-3.3 ; 3.3)$ & $0 ; 0$ & $-2.9 ; 3.6$ \\
\hline \multirow[t]{2}{*}{ Point $8(n=47)$} & & 106 & $106.7(103.3-106.7)$ & $-0.7(-6.0 ; 2.7)$ & $-0.7 ;-0.7^{*}$ & $-3.2 ; 3.4$ \\
\hline & 3: Greater trochanter & & & & & \\
\hline Point 9 & & 140 & $146.7(|42.0-| 46.7)$ & $0(-0.7 ; 0)$ & $0 ; 0$ & $-0.2 ; 0.2$ \\
\hline Point $10(n=49)$ & & 70 & $71.7(66.7-73.3)$ & $0(-3.3 ; 3.3)$ & $0 ; 3.3$ & $-2.3 ; 4.8$ \\
\hline Point II & & 20 & $20(13.3-30.0)$ & $0(-6.7 ; 0)$ & $0 ; 0$ & $-2.3 ; 1.9$ \\
\hline Point 12 & & 10 & $10(6.7-13.3)$ & $0(-3.3 ; 3.3)$ & $0 ; 0$ & $-2.5 ; 2.7$ \\
\hline Point 13 & & 70 & $70(66.7-73.3)$ & $0(-6.7 ; 3.3)$ & $0 ; 0$ & $-3.7 ; 4.3$ \\
\hline \multirow[t]{2}{*}{ Point I4 $(n=49)$} & & 105 & $106.7(106.7-106.7)$ & $-1.7(-1.7 ; 1.7)$ & $-1.7 ;-0.3 *$ & $-8.7 ; 8.6$ \\
\hline & 4: Mid knee & & & & & \\
\hline Point 15 & & 50 & $53.3(40-66.7)$ & $0(-3.3 ; 10.0)$ & $0 ; 0$ & $-3.4 ; 4.9$ \\
\hline Point 16 & & 10 & $10(6.7-13.3)$ & $0(-3.3 ; 3.3)$ & $0 ; 0$ & $-2.9 ; 3.6$ \\
\hline Point 17 & & 40 & $40(40-42)$ & $0(0 ; 0)$ & $0 ; 0$ & $0 ; 0$ \\
\hline \multirow[t]{2}{*}{ Point I8 $(n=49)$} & & 85 & $86.7(86.7-90)$ & $-1.7(-1.7 ; 5.0)$ & $-1.7 ;-1.7^{*}$ & $-3.6 ; 0.7$ \\
\hline & 5: Lateral malleolus & & & & & \\
\hline Point 19 & & 60 & $63.3(60-66.7)$ & $0(-1.3 ; 0)$ & $0 ; 0$ & $-0.5 ; 0.4$ \\
\hline Point 20 & & 60 & $63.3(60-63.3)$ & $0(-1.3 ; 0)$ & $0 ; 0$ & $-0.4 ; 0.4$ \\
\hline Photo 2 & I: External auditory meatus & & & & & \\
\hline Point I & & 40 & $40(33.3-40.7)$ & $0(-0.7 ; 0.7)$ & $0 ; 0$ & $-1.8 ; 2.0$ \\
\hline Point 2 & & 21 & $20.0(20-26.7)$ & $1.0(-5.7 ; 1.0)$ & $1 ; 1 *$ & $-1.0 ; 2.8$ \\
\hline Point 3 & & 30.5 & $30(26.7-33.3)$ & $0.5(-2.8 ; 3.8)$ & $0.5 ; 0.5 *$ & $-1.5 ; 3.3$ \\
\hline \multirow[t]{2}{*}{ Point 4} & & 61 & $60(58.3-60.0)$ & $1.0(1.0 ; 2.7)$ & $1 ; I^{*}$ & $0.5 ; 1.6$ \\
\hline & 2: Acromion & & & & & \\
\hline Point 5 & & 106 & $106.7(106.7-113.3)$ & $-0.7(-7.3 ;-0.7)$ & $-0.7 ;-0.7^{*}$ & $-2.7 ; 1.1$ \\
\hline Point 6 & & 50 & $50(46.7-53.3)$ & $0(-3.3 ; 3.3)$ & $0 ; 0$ & $-2.6 ; 2.5$ \\
\hline Point 7 & & 50 & $50(46.7-53.3)$ & $0(-3.3 ; 3.3)$ & $0 ; 0$ & $-1.9 ; 2.2$ \\
\hline \multirow[t]{2}{*}{ Point 8} & & 106 & $106.7(103.3-106.7)$ & $-0.7(-0.7 ; 32.7)$ & $-0.7 ;-0.7^{*}$ & $-12.1 ; 14.2$ \\
\hline & 3: Greater trochanter & & & & & \\
\hline Point 9 & & 140 & 146.7 (I42.0-| 46.7$)$ & $-6.7(-6.7 ;-2.0)$ & $-6.7 ;-6 *$ & $-8.6 ;-2.6$ \\
\hline Point 10 & & 70 & $71.7(66.7-73.3)$ & $-1.7(-3.3 ; 3.3)$ & $-3.3 ; 0$ & $-5.1 ; 1.9$ \\
\hline Point II & & 20 & $20(13.3-30.0)$ & $0(-10.0 ; 6.7)$ & $0 ; 0$ & $-3.5 ; 3.4$ \\
\hline Point 12 & & 10 & $10(6.7-13.3)$ & $0(-20.0 ; 3.3)$ & $0 ; 0$ & $-6.4 ; 5.9$ \\
\hline Point 13 & & 70 & $70(66.7-73.3)$ & $0(-3.3 ; 3.3)$ & $0 ; 0$ & $-3.8 ; 2.5$ \\
\hline \multirow[t]{2}{*}{ Point 14} & & 105 & $106.7(106.7-106.7)$ & $-1.7(-1.7 ;-1.7)$ & $-1.7 ;-1.7 *$ & $-1.7 ;-1.7$ \\
\hline & 4: Mid knee & & & & & \\
\hline Point I5 & & 50 & $53.3(40-66.7)$ & $-3.3(-16.7 ; 10.0)$ & $-3.3 ; 3.3$ & $-9.2 ; 3.8$ \\
\hline
\end{tabular}


... table continued from page 44

\begin{tabular}{|l|l|c|c|c|c|c|}
\hline Point 16 & & 10 & $10(6.7-13.3)$ & $0(-3.3 ; 3.3)$ & $0 ; 0$ & $-2.4 ; 3.4$ \\
\hline Point I7 & & 40 & $40(40-42)$ & $0(-2.0 ; 0)$ & $0 ; 0$ & $-1.0 ; 0.8$ \\
\hline Point 18 & & 85 & $86.7(86.7-90)$ & $-1.7(-5.0 ; 31.7)$ & $-1.7 ;-1.7^{*}$ & $-14.3 ; 12.8$ \\
\hline & 5: Lateral malleolus & & & & & \\
\hline Point 19 & & 60 & $63.3(60-66.7)$ & $-3.3(-6.7 ; 0)$ & $-3.3 ;-3.3^{*}$ & $-6.1 ; 0.1$ \\
\hline Point 20 & & 60 & $63.3(60-63.3)$ & $-3.3(-3.3 ; 0)$ & $-3.3 ;-3.3^{*}$ & $-5.2 ; 0.3$ \\
\hline
\end{tabular}

* Statistical significant difference

Table II: Differences between photos regarding the distance measured and actual distance in $\mathrm{mm}(\mathrm{n}=50)$

\begin{tabular}{|c|c|c|c|c|}
\hline Variable & Anatomical landmarks & $\begin{array}{l}\text { Median difference in } \\
\text { mm's (range) }\end{array}$ & $\begin{array}{l}95 \% \mathrm{Cl} \text { for the median } \\
\text { difference for paired data }\end{array}$ & $95 \%$ limits of agreement \\
\hline & I: External auditory meatus & & & \\
\hline Point I & & $0(0 ; 6.7)$ & $0 ; 0$ & $-3.1 ; 3.9$ \\
\hline Point 2 & & $0(-6.7 ; 0)$ & $0 ; 0$ & $-2.9 ; 2.5$ \\
\hline Point 3 & & $0(-6.7 ; 3.3)$ & $0 ; 0$ & $-5.1 ; 3.6$ \\
\hline \multirow[t]{2}{*}{ Point 4} & & $0(-1.7 ; 0)$ & $0 ; 0$ & $0 ; 0$ \\
\hline & 2: Acromion & & & \\
\hline Point 5 & & $0(0 ; 53.3)$ & $0 ; 0$ & $-1.2 ; 1.7$ \\
\hline Point 6 & & $1.3(-3.3 ; 13.3)$ & $0 ; 3.3$ & $-2.7 ; 4.3$ \\
\hline Point 7 & & $0(-6.7 ; 6.7)$ & $0 ; 0$ & $-3.9 ; 4.9$ \\
\hline \multirow[t]{2}{*}{ Point 8} & & $0(-33.3 ; 33.3)$ & $0 ; 0$ & $-3.1 ; 4.1$ \\
\hline & 3: Greater trochanter & & & \\
\hline Point 9 & & $6.7(2 ; 33.3)$ & $6 ; 6.7^{*}$ & $-1.1 ; 5.6$ \\
\hline Point 10 & & $3.3(-30 ; 6.7)$ & $2 ; 3.3^{*}$ & $-1.6 ; 7.8$ \\
\hline Point II & & $0(-6.7 ; 10)$ & $0 ; 0$ & $-1.0 ; 0.9$ \\
\hline Point 12 & & $0(-3.3 ; 20)$ & $0 ; 0$ & $-3.3 ; 4.5$ \\
\hline Point 13 & & $0(-6.7 ; 6.7)$ & $0 ; 0.7$ & $-3.5 ; 8.4$ \\
\hline \multirow[t]{2}{*}{ Point I4 } & & $0(0 ; 30)$ & $0 ; 1.3$ & $-1.8 ; 4.4$ \\
\hline & 4: Mid knee & & & \\
\hline Point 15 & & $3.3(-6.7 ; 16.7)$ & $3.3 ; 3.3 *$ & $-5.9 ; 7.8$ \\
\hline Point 16 & & $0(-6.7 ; 3.3)$ & $0 ; 0$ & $-1.9 ; 2.5$ \\
\hline Point 17 & & $0(0 ; 2)$ & $0 ; 0$ & $-0.6 ; 0.8$ \\
\hline \multirow[t]{2}{*}{ Point 18} & & $0(-66.7 ; 6.7)$ & $0 ; 0$ & $-1.9 ; 2.5$ \\
\hline & 5: Lateral malleolus & & & \\
\hline Point 19 & & $3.3(0 ; 6.7)$ & $3.3 ; 3.3^{*}$ & $-1.6 ; 5.8$ \\
\hline Point 20 & & $3.3(0 ; 3.3)$ & $3.3 ; 3.3^{*}$ & $-1.3 ; 5.5$ \\
\hline
\end{tabular}

* Statistical significant difference

Although statistically significant differences (95\% confidence interval for the difference) were found when the two photos were compared (vary within $7 \mathrm{~mm}$ ), no clinically significant differences were found as it fell within $10 \mathrm{~mm}$.

In addition to the confidence interval difference, the limits of agreement indicate that the measurement methods are similar as the agreement deviates within $10 \mathrm{~mm}$, which has the clinical implication that the measurements do not differ from the actual values.

\section{DISCUSSION}

With the need for evidence to advance quality health care service delivery, researchers need to provide research results that are clinically relevant and have an impact on decision making in order to enhance evidence-based practice.

Graphical representation of body measurement of the whole body allows for the "derivative" measurements in research ${ }^{22}$. The
P-MPA is similar to the 'moiré' projection technique ${ }^{22}$, of a spatial object with limited depth, leading to the formation of a 'moiré' topography on the object surface.

Consistent with contemporary calls for validity and reliability ${ }^{13,14}$, results from the current study reflect content validity of the P-MPA, which was further evaluated for construct validity, and reported in terms of accuracy. This current study also reports on the intra-rater reliability in terms of consistency reflected in the measurements of deviations from the plumb line.

In order to establish content validity ${ }^{23}$ the graph used in the current study represented the five anatomical landmarks which is depicted by means of horizontal lines, and 20 points plotted on the horizontal lines indicating the possible range in distance deviation from the plumb line. Consistent with the plumb line observational method of assessment of posture ${ }^{19}$ these five horizontal lines were representative of the anatomical landmarks used in the assessment 
of posture namely lateral malleolus, knee, greater trochanter, acromion and external auditory meatus. Face validity was reflected by the representation of the constructs of the anatomical landmarks on the graph, which reflected the dimensions of a person of $1.6 \mathrm{~m}$ in height as well as the range in distances of the 20 points plotted on the horizontal lines. Construct validity was ensured by using a ratio to calculate the actual distances between the anatomical landmarks and the points on the horizontal lines in relation to the plumb line.

Similar to the research performed by authors Grosso, Negrini, Boniolo and Negrini ${ }^{23}$ a clinically significant difference in the current study was set at $10 \mathrm{~mm}$ to compensate for physiologic responses in the short term. From a practice perspective, a clinically significant difference value of $10 \mathrm{~mm}$ from the reference point was considered to accommodate for minor postural re-adjustments that a person makes after a position had been assumed, as is often seen in clinical practice in preparation for postural assessment. No other laboratory studies, with similar objectives, were found that specify a clinical value for comparison.

Contrary to the design of other studies, the advantage of this study was that the actual deviation from the plumb line was a constant and known measure to compare to, which contributes to construct validity. In comparison to evidence from existing studies $^{10,24,25}$ the P-MPA is a valid instrument to measure posture, considering that the measured distances (in Table II on page 45) deviate within $10 \mathrm{~mm}$ from the actual values.

In line with the Cosmin's theory of reliability, the P-MPA has good reproducibility as indicated by the $95 \%$ confidence intervals and limits of agreement (in Table II) and can therefore be repeatedly used by different users as no clinically significant differences were found between measurements, as performed by the 50 participants. The high level of accuracy of the P-MPA has been demonstrated, and results on reliability reflect both accuracy and repeatability, which according to Altman ${ }^{20}$, justifies good agreement.

The estimated limits of agreement indicate how large disagreements between methods measurements will be on $95 \%$ of occasions. As seen in the results of this study, the measurements do not differ clinically significantly which confirms the P-MPA to be a reliable inter-rater measurement instrument to use.

The statistical significant distance deviations between measured and actual distances observed at the extremities of the anatomical landmarks could be due to measurement error of the camera lens. This was also noted by Strzecha et $\mathrm{a}^{26}$, with the analysis of photogrammetric systems that showed that none of these systems features options of automated adjustment of the camera height, which were not equipped in distance sensors (rangefinders). Distance sensors allow for precision measurement of the distance of a selected body part of a patient from the camera lens. However, in the current study, differences between measured and actual values are clinically insignificant and the P-MPA can, therefore, be used as a measurement tool for the assessment of posture.

Finally, contrary to the subjective nature of qualitative reporting when using the plumb line method of posture assessment, results from this study indicate that the P-MPA is valid and reliable as a quantitative method for the assessment of posture.

\section{CONCLUSION}

Results from this study show that the method of postural assessment (P-MPA) can be used as a valid (face, content and construct validity) and reliable method in a clinical context for the assessment of postural alignment.

\section{RECOMMENDATION}

It is recommended that the P-MPA be used, as a user-friendly and cost-effective method, for measuring postural alignment in both clinical settings and research studies. The authors recommend that the P-MPA be investigated further regarding its reproducibility; firstly comparing different postural alignments from different patients measured by different therapists within the clinical context, and secondly, determine the lack of camera lens range-finding function by using more cameras and that the photos be measured more than once by the same therapists. Lastly, we recommend that the P-MPA be further developed and investigated as a measurement tool in both single and multiple-joint research studies such as in the alignment of hand and wrist joints during activity performance.

\section{ACKNOWLEDGEMENTS}

The authors acknowledge the contribution of Professor P Blignaut from the department of Computer Science and Informatics at the University of the Free State during the conceptual phase of the study, Mr. R Setenane of CTL for the figure compilation and the study participants.

\section{REFERENCES}

I. Inoue $\mathrm{N}$, Orias AAE. Biomechanics of the Intervertebral disc Degeneration. Orthopedic Clinics of North America, 201 I, 42(4): 487-499. https://doi.org/10.1016/j.ocl.20II.07.00I.

2. Rohlman A, Pohl D, Bender A, Graichen F, Dymke J, Schmidt H, Gergman G. Activities of Everyday Life with High Spinal Loads. 2014 PLOS Tenth Anniversary. PLoS ONE9(5): e985I0. https://dx.doi.org//0.137|/journal.pone.00985।0.

3. O'Sullivan K, Galeotti L, Dankaerts W, O'Sullivan L, O'Sullivan P. The between-day and inter-rater reliability of a novel wireless system to analyse lumbar spine posture. Ergonomics, 20I I; 54(I): 82-90. https://dx.doi.org/I0.1080/ool40139.2010.53502.

4. Brink Y, Louw Q. Grimmer-Somers K. The quality of evidence of psychometric properties of three-dimensional spinal posturemeasuring instruments. BMC Musculoskeletal Disorders, 20I I; I2(I): 93-I03. https://dx.doi.org//0.1 I86//47|-2474-12-93.

5. Lee CB, Kim GH, Lee SK. Design and construction of a single unit multi-function optical encoder for a six-degree-of freedom motion error measurement in an ultra-precision linear stage. Measurement Science and Technology, 20I I; 22(I0): 10590I. https://doi.org/I0.1088/0957-0233/22/10/10590I.

6. Poitras S, Blais R, Swaine B, Rossignol M. Management of workrelated low back pain: a population-based survey of physical therapists. Physical Therapy, 2005; 85(I I): I I68-I I8I https://doi.org//0.1093/ptj/85.II.II68.

7. Dankaerts W, O'Sullivan P, Burnett A, Straker L. Differences in sitting postures are associated with non-specific chronic low back pain disorders when sub-classified. Spine, 2006a; 3I(6): 698-704. https://dx.doi.org/10.1097/0I.brs.0000202532.76925.d2

8. Castro JL, Medina-Carnicer R Galisteo AM. Design and evaluation of a new three-dimensional motion capture system based on video. Gait \& Posture, 2006; 24(I): I26-129. https://doi.org/I0.1016/j.gaitpost.2005.08.00I

9. Mundermann L, Corazza S, Andriacchi TP. 2006. The evolution of methods for the capture of human movement leading to markerless motion capture for biomechanical applications. Journal of Neuroengineering and Rehabilitation, 2006; 3:6. https://doi.org/I0.I I 86/I743-0003-3-6.

10. Hough R, Nel M. Intra-Rater Reliability of the Posture Analysis Tool kit. South African Journal of Occupational Therapy, 2013. 43(I): 15-20. Available from: http://www.scielo.org.za/scielo. php?script=sci_arttext\&pid=S23 I0-383320| $3000 \mid 00004 \& I n g=e n$.

II. Rosario JL: Biomechanical assessment of human posture: a literature review. J Bodyw Mov Ther. Jul; 18 (3): 368-73. https://doi.org//0.1016/j.jbmt.2013.11.018.

12. Singla $D$ and Vegar Z. Methods of Postural Assessment Used for Sports Persons. J Clin Diagn Res. 2014 Apr; 8(4): LEOI-LE04. https://doi.org/I0.7860/JCDR/20|4/6836.4266.

13. Mokkink LB, Terwee CB, Patrick DL, Alonso J, Stratford PW, Knol DL, Bouter LM, de Vet HCW. The COSMIN checklist for assessing the methodological quality of studies on measurement properties of health status measurement instruments: an international Delphi study. Quality of life research, 2010. 19(4): 539-549. https://doi.org/10.1007/s I I |36-010-9606-8.

14. Huck SW. Reading Statistics and Research. Sixth Edition. Boston: Pearson, 2012: 81.

15. White SA, Van den Broek NR. Methods for assessing reliability and validity for a measurement tool: a case study and critique using the 
WHO haemoglobin colour scale, 2004; 23:1603-1619.

https://doi.org/I0.1002/sim.4780I32310.

16. Mokkink LB, Terwee CB, Patrick DL, et al. The COSMIN checklist for assessing the methodological quality of studies on measurement properties of health status measurement instruments: an international Delphi study. Qual Life Res, 2010; 539-49.

https://doi.org/I0.1007/s I I |36-010-9606-8.

17. Terwee CB, Mokkink LB, Knol DL, Ostelo RW, Bouter LM, de Vet $\mathrm{HC}$. Rating the methodological quality in systematic reviews of studies on measurement properties: a scoring system for the COSMIN checklist. Qual Life Res, 20I2; 2 I (4): 65I-657. https://doi.org/I0.1007/s I I |36-0I I-9960-I.

18. Kendall FP McCreary EK, Provance PG. Muscle testing and function with posture and pain. $5^{\text {th }}$ ed. Baltimore: Lippincott, Williams \& Wilkins, 2005: 59-63.

19. Altman DG. Practical statistics for medical research. London: Chapman \& Hall, 1996: 402.

20. Armijo-Olivo S, Warren S, Fuentes J, Magee DJ. Clinical relevance vs. statistical significance: Using neck outcomes in patients with temporomandibular disorders as an example. Manual Therapy. 20II; 16: 563-572. https://doi.org/I0.1016/j.math.20II.05.006

21. Bland JM, Altman DG. Applying the right statistics: analyses of measurement studies. Ultrasound Obstetric Gynecology, 2003; 22: 85-93. https://doi.org/I0.1002/uog. 122.

22. Grosso C, Negrini S, Boniolo A, Negrini A. The validity of the clinical examination in adolescent spinal deformities. Studies in Health Technology Informatics. 2002; 91:123-5.

23. Kosse NM, Caljouw S, Vervoort, D, Vuillerme N, Lamoth CJC. Annals of Biomedical Engineering. 20I5; 43: 1935. https://doi.org/10.1007/s 10439-0I4-1232-0.

24. Jaeschke L, Steinbrecher A, Pischon T. Measurement of waist and hip circumference with a body surface scanner: feasibility, validity, reliability, and correlations with markers of the metabolic syndrome. PLoS ONE 2015; I0(3): 30II 19430.

https://doi.org/I0.137I/journal.pone.01 19430.

25 Strzecha M, Knapik H, Baranovski P, Pekala A, Pasiak J. Clinical significance of measurement reliability of diagnostic tools used for evaluation of body posture. Rehabilitacja w praktyce. 20I4; 4:28-32.

\section{Corresponding Author}

*P A Hough

houghpa@ufs.ac.za 